Удк 616.216.3:616-039

\section{А.А. Блоцкий, В.В. Антипенко}

ФГБОУ ВО Амурская ГМА

Минздрава России

г. Благовещенск

\section{РЕДКОЕ ЗАБОЛЕВАНИЕ ОСНОВНОЙ} ПАЗУХИ

Мукоцеле - это кистовидное растяжение околоносовых пазух, характеризующееся накоплением в них содержимого и растяжением их костных стенок вследствие закрытия выводных отверстий. Содержимым мукоцеле может быть слизистый и гиалиновый секрет с элементами десквамации эпителия.

Мукоцеле околоносовых пазух относится к редко встречающимся заболеваниям. По данным В.И. Бабияк, Я.А. Накатис (2005) мужчины болеют чаще в возрасте 15-25 лет, при этом возраст, наиболее подверженный патологии, 10-45 лет [1]. В литературе по частоте встречаемости на первом месте стоит лобная пазуха - 80\% случаев, реже - решетчатая, приблизительно $15 \%$, еще реже - основная и гайморова пазухи, около 5\% [2-7]. В 1923 г. Гофман нашел в мировой литературе всего 9 случаев описания этого заболевания. По данным А. Лангера и Т. Олина (1962), в литературе описано 55 наблюдений мукоцеле основной пазухи и задних решеток [8].

На стадии клинических проявлений данного заболевания возможно развитие таких осложнений, как экзофтальм, диплопия, неврит зрительного нерва, боли в глазном яблоке, в последующем - снижение зрения и слепота. Нередко глазничные проявления являются первыми и наиболее постоянными симптомами.

Причиной мукоцеле считают нарушение сообщения пазухи с полостью носа. Это нарушение может быть первичным, например, явиться результатом травмы с кровоизли- янием в слизистую оболочку или под нее с последующим рубцеванием, или вторичным, например, возникнуть на фоне хронического воспаления в пазухе и вызванной им облитерации выводного отверстия [6]. Сегодня данные механизмы объединили в так называемую «компрессионную» теорию, по которой банальная закупорка выводящих протоков, образование агрессивного содержимого и активизация остеокластов приводят к разрушению костных стенок пазухи. По другой, «моногландулярной», теории происходит закупорка одной слизистой железы, в результате происходит ее расширение, пролиферация эпителиального слоя и образование слизистого мешка [1].

В качестве клинического примера приводим историю болезни больной В., 31 г., которая находилась на лечении в ЛОР-отделении Амурской областной клинической больницы (АОКБ) г. Благовещенска с 15.04.2015 по 29.04.2015 Г.

Поступила с жалобами на постоянные головные боли разлитого характера, повышенную утомляемость, слабость, нарушение сна из-за болей.

Анамнез заболевания. Появления головных болей отмечает с апреля 2014 года, связывает с перенесенной вирусной инфекцией. Головные боли самостоятельно не купировались: с этого времени пациентка постоянно принимает нестероидные противовоспалительные препараты. В апреле 2015 г. было выполнено КТ-исследование головного мозга, на котором выявлены признаки сфеноидита левой основной пазухи, новообразования левой основной пазухи. Госпитализирована в ЛОР-отделение.

При осмотре риноскопически слизистая оболочка полости носа умеренно отечна, с цианотичным оттенком, отделяемого нет, носовая перегородка искривлена с обеих сторон в виде гребня, носовое дыхание компенсировано.

Эндоскопический осмотр полости носа и носоглотки: технически затруднен из-за выраженного искривления носовой перегородки в костном отделе, слизистая оболочка полости

\title{
PЕЗЮME
}

Одним из редко встречающихся заболеваний основной пазухи является ее кистовидное растяжение. До настоящего времени в литературе описано 55 наблюдений кистовидного растяжения (мукоцеле) основной пазухи и задних решетчатых пазух. Мукоцеле основной пазухи может приводить к появлению у пациента постоянных головных болей в затылочной области с последующим развитием ряда осложнений - экзофтальм, диплопия, неврит зрительного нерва, боли в глазном яблоке, снижение зрения и слепота.

Представляем клинический случай наблюдения больной с мукоцеле основной пазухи как редкого патологического процесса с данной локализацией, с возможным развитием грозных осложнений, трудностями хирургического доступа при выборе метода лечения.

Ключевые слова: мукоцеле основной пазухи, хроническое воспаление основной пазухи, глазничные осложнения, хирургическое лечение. DOI 10.22448/AMJ.2017.2.68-71 

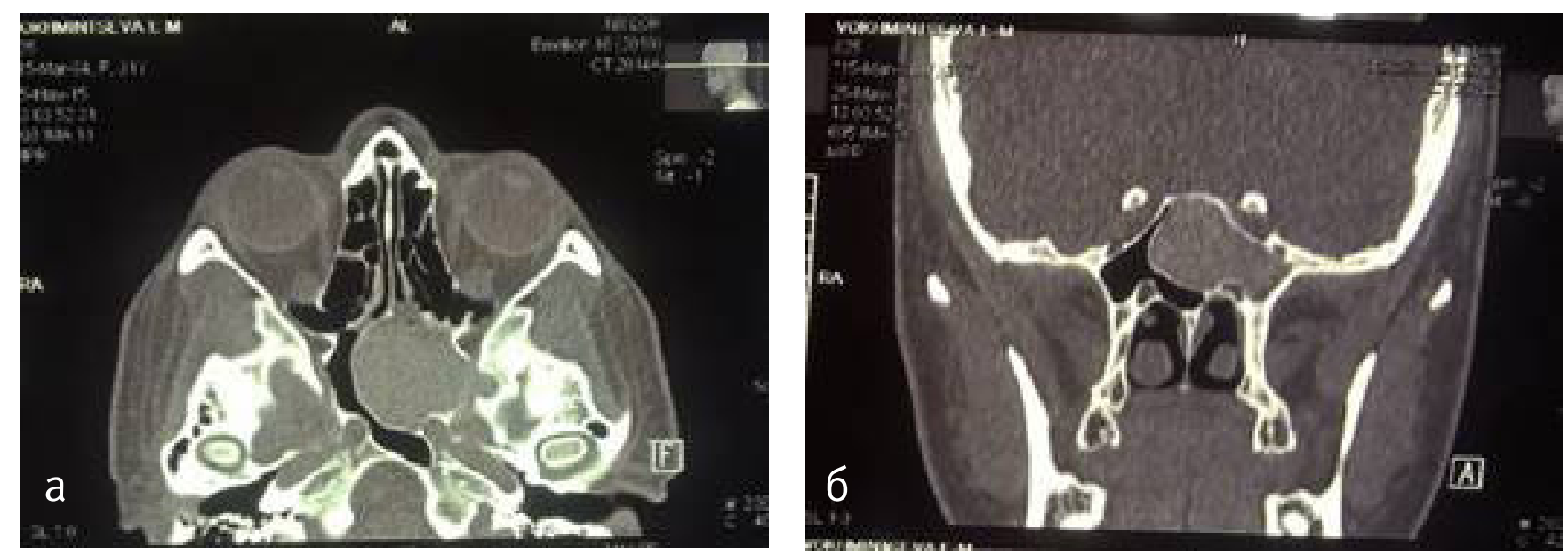

Рисунок 1. КТ олколоносовых пазух больной В., 31 год. a - аксиальная проекция, б - фронтальная проекция (признаки новообразования основной пазухи слева).

носа не изменена, «плюс» - ткани не определяется.

Выполнена КТ околоносовых пазух 20.04.2015: левая клиновидная пазуха тотально выполнена неоднородным содержимым (плотность $+110 \mathrm{HU})$ неоднородного характера за счет наличия фрагментов газа. Стенки левой клиновидной пазухи истончены, без признаков деструкции (рис. 1).

Для уточнения вида новообразования дополнительно применен метод визуализации МРТ с контрастированием (в,в Омнискан 20 мл). Цель методики - выявить накопление контраста в стенках новообразования, определить наличие сосудистого рисунка, прорастание опухоли. В основной пазухе слева определялось содержимое с неоднородным гипоинтенсивным сигналом, близко расположенное к левому глазному нерву. Стенки пазухи без признаков деструкции. После введения контраста отмечалось равномерное накопление его воспаленной слизистой, признаков опухоли не определялось. Данные исследования позволили подтвердить предполагаемый диагноз мукоцеле (рис. 2).

Прошла курс противовоспалительной, антибактериальной, десенсибилизирующей терапии, курс местного лечения с применением синус-катетера ЯМИК № 5 процедур, без динамики.
Подтверждён диагноз: хронический левосторонний сфеноидит; мукоцеле левой основной пазухи. Рекомендовано удаление новообразования (мукоцеле) основной пазухи по ВМП на центральной базе.

С 25.05 по 08.06.2015 г. на базе Санкт-Петербургского НИИ уха, горла, носа и речи проведено хирургическое лечение: удаление новообразования с применением навигационной техники и эндоваскулярной эмболизации сосудов микро-эмболами и при помощи адгезивного агента в условиях ЭТН.

Послеоперационный период протекал без особенностей. Реабилитационных мероприятий не требовалось, пациентка выписана к труду. В послеоперационном периоде отмечалась положительная динамика: исчезли головные боли, улучшилось общее самочувствие, пациентка отказалась от приема НПВС. В отдаленном послеоперационном периоде проводились контрольный эндоскопический осмотр (рис. 3) и МРТ ОНП (рис. 4), на которых признаки послеоперационных изменений основной пазухи слева и полости носа слева, данных за рецидив новообразования не выявлено.

Таким образом, интерес представленного клинического случая заключается в локализации патологического процесса, очень редкой его распространённости, трудностью хирур-

\section{RARE DISEASE OF THE SPHENOID SINUS}

A.A. Blotsky, V.V. Antipenko

Amur State Medical Academy,

Blagoveshchensk

\section{ABSTRACT}

Cystoid dilatation of the sphenoid sinus is one of the rare diseases. In the literature only 55 descriptions of the cystic extension of the sphenoid sinus and posterior ethmoid sinuses were found. Mucocele of the sphenoid sinus can lead to permanent headaches in the occipital region, exoph-thalmos, diplopia, optic neuritis, pain in the eyeball, loss of vision and blindness. The article pre-sents a clinical case of a patient with a mucocele of the main sinus. The complexity of the case lies in the difficulty of surgical access when choosing a method of treatment.

Key words: mucocele of the sphenoid sinus, chronic inflammation of the main sinus, ocu-lar complications, surgical treatment. 

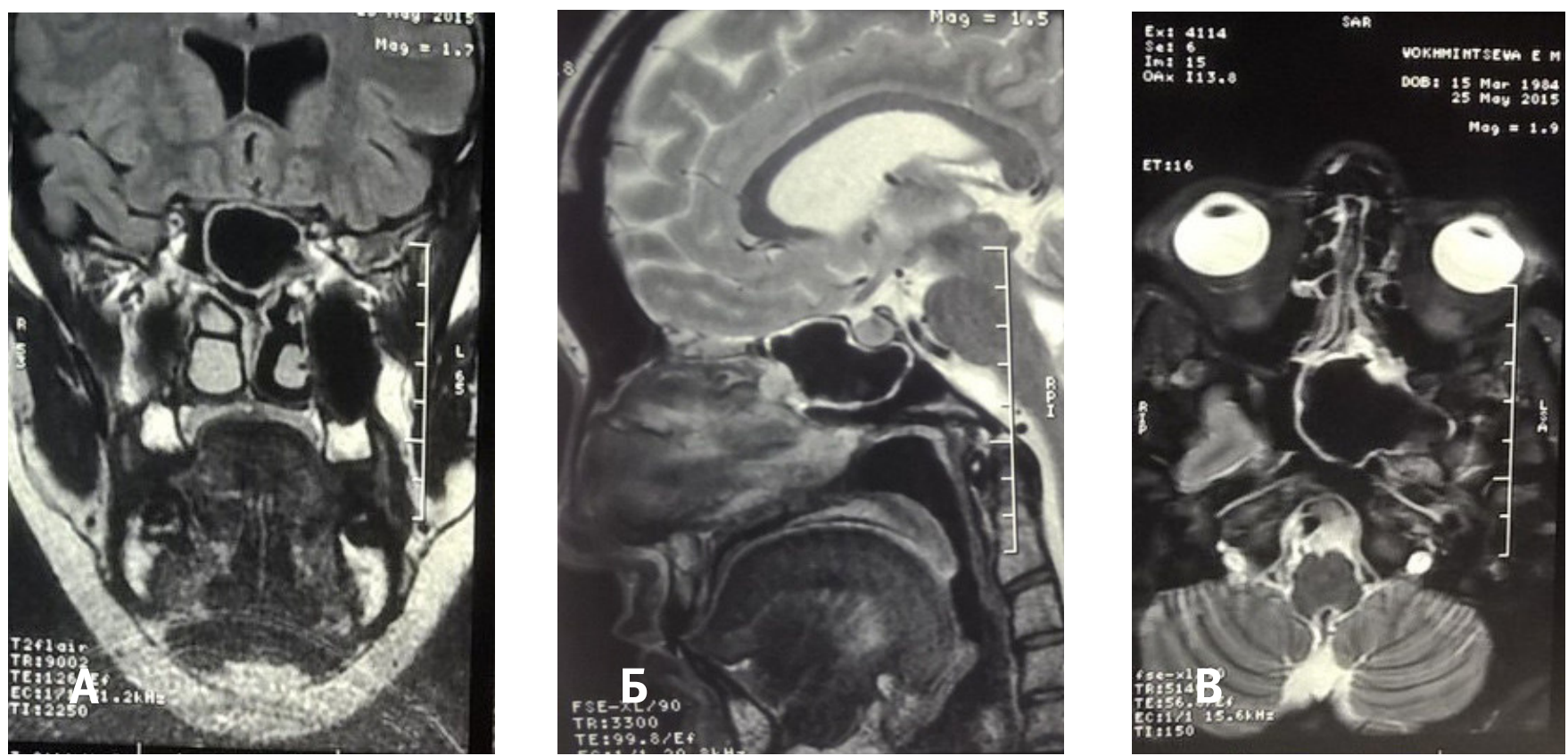

Рисунок. 2. МРТ черепа с контрастом больной В., 31 год.

а - фронтальная проекция, б - саггитальная проекция, в - аксиальная проекция («симптом пустой пазухи», стенки без признаков деструкции).
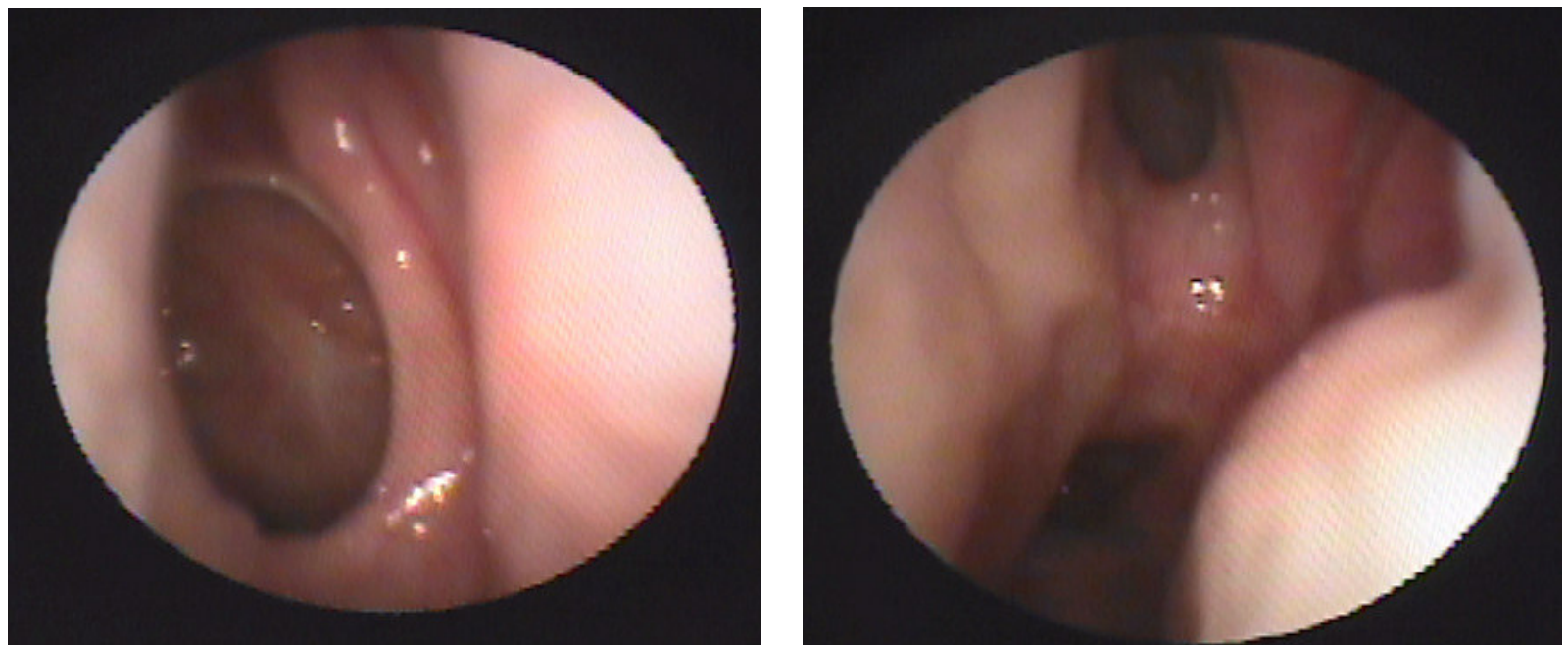

Рисунок. 3. Эндоскопическая картины полости носа больной В., 31 год, после операции.
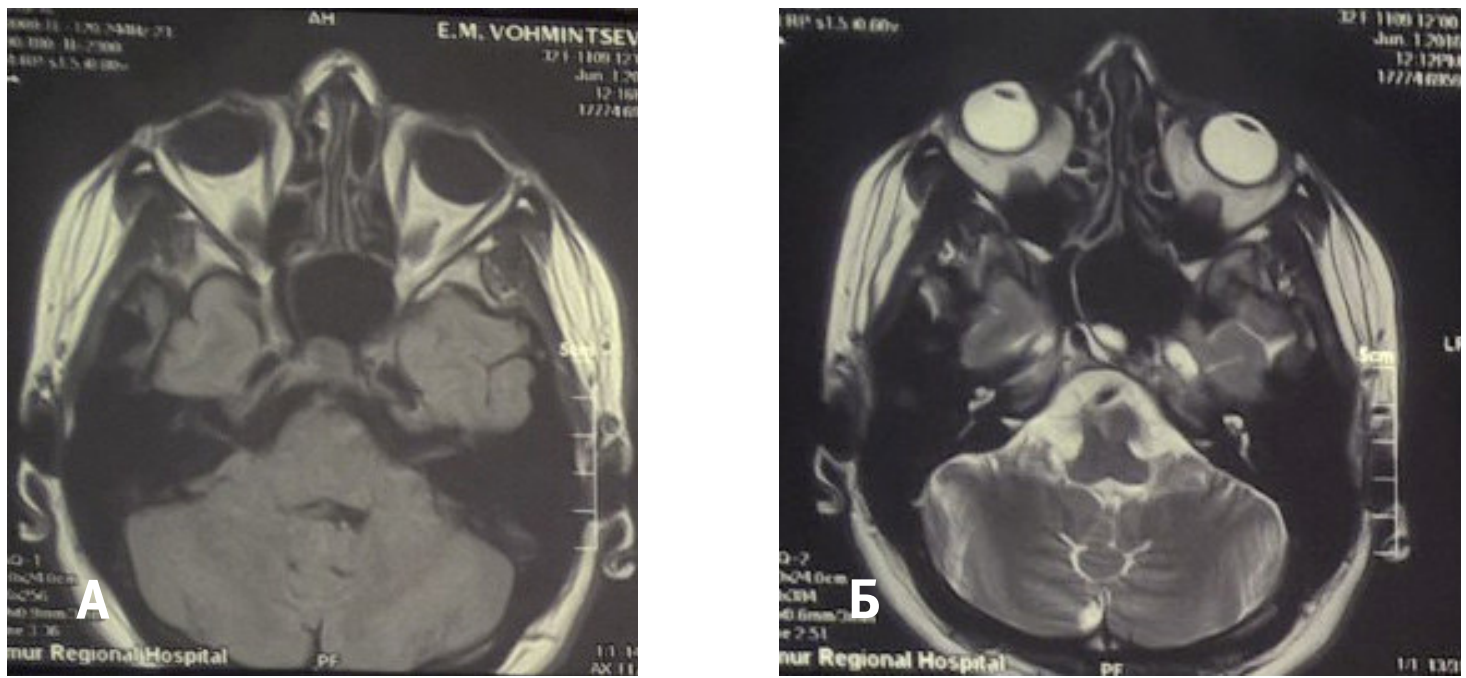

Рисунок. 4. МРТ околоносовых пазух больной В., 31 год, после операции a - фронтальная проекция, 6 - саггитальная проекция, в - аксиальная проекция («симптом пустой пазухи», стенки без признаков деструкции). 
гического доступа при выборе лечения.

\section{Литература}

1. Бабияк В.И, Накатис Я.А. Клиническая оториноларингология. Руководство для врачей / В.И. Бабияк, Я.А. Накатис . СПб.: Гиппократ. 2005. 797 C.

2. Блоцкий A.A. Мукоцеле лобной пазухи / A.A. Блоцкий // Folia Otorhinolaryngologiae et Pathologiae Respiratoriae. 2009. Vol. 15. №2. P. 3438 .

3. Блоцкий А.А. Мукоцеле лобной и верхнечелюстной пазухи / А.А. Блоцкий, М.Ю. Цепляев // Материалы межрегион. научно-практич. конф. оторинолар. Сибири и Дальнего Востока «Актуальные вопросы оториноларингологии». Благовещенск, 2009. С. 42-48.

4. Блоцкий А.А. Гигантское мукоцеле верхнечелюстной пазухи / А.А. Блоцкий, Н.В. Валова, П.П. Тюриков и соавт. // Материалы межрегион. научно-практич. конф. оторинолар. Сибири и Дальнего Востока «Перспективы научно-практической оториноларингологии». Благовещенск, 2010. С. 68-70.

5.Блоцкий А.А. Мукоцеле лобной и верхнечелюстной пазухи / А.А. Блоцкий, М.Ю. Цепляев // Folia Otorhinolaryngologiae et Pathologiae Respiratoriae. 2014. Vol.20. №4. P. 62-65.

6. Лихачев А.Г. Руководство по оториноларингологии / А.Г. Лихачев. Москав.: Медицинская литература. 1963. С. 123-133.

7. Солдатов И.Б. Руководство по оториноларингологии / И.Б. Солдатов. Москва: Медицина. 1994. 608 с.

8. Lundgren A., Olin T. Muco-Pyocele of sphenoidal sinus or posterior ethmoidal cels with spe-cial reference to the apex orbitae syndrome / A. Lundgren, T. Olin // Acta Oto-laryng. 1962/ 53, 1. P. 61-79.

Статья поступила 10.05.2017

\section{Координаты для связи}

Блоцкий Александр Антонович, д.м.н., профессор, зав. кафедрой оториноларингологии и офтальмологии ФГБОУ ВО Амурская ГМА Минздрава России. E-mail:blotskiy@gmail.com

Антипенко Виктория Викторовна, к.м.н., ассистент кафедры оториноларингологии и офтальмологии ФГБОУ ВО Амурская ГМА Минздрава России.

Почтовый адрес ФГБОУ ВО Амурская ГМА Минздрава России: 675000, г. Благовещенск, ул. Горького, 95. E-mail: amurgma@list.ru, agma@nm.ru 